\title{
Effects of testing techniques on the SWRC of a partially saturated soil
}

\author{
Xiwei Zhang ${ }^{1,2}$, Maria Mavroulidou ${ }^{1, a}$ and Michael J. Gunn ${ }^{1}$ \\ ${ }^{1}$ London South Bank University, SE1 OAA, UK \\ ${ }^{2}$ Northeastern University, Shenyang, Liaoning, 110819, P.R. China
}

\begin{abstract}
The paper studies the laboratory measurement of the Soil Water Retention Curve (SWRC) of statically compacted London Clay focusing on the effects of different specimen preparation methods and testing techniques to acquire a better understanding of how measurements can be affected by these factors. Testing methods include filter paper, two modified pressure plate systems, and a ceramic pressure membrane extractor. A discussion on the repeatability of the measurements is also made.
\end{abstract}

\section{Introduction}

In view of its major importance in the context of unsaturated soil mechanics, the soil water retention behaviour of natural soils in various forms (mostly after compaction or in reconstituted form) as expressed by their soil water retention curve (SWRC) has been extensively investigated. The form of the curve was shown to depend on a number of factors including soil structure, stress history and state, initial water content and void ratio of compacted soils, chemistry of the pore-fluid, volume change of the soil through swelling, shrinkage, loading or unloading, and wetting or drying paths.

In this study we focus the investigation on the possible effects of a number of factors related to experimental procedures and equipment, namely a) saturation procedures of compacted specimens prior to drying SWRC testing; b) comparison between filter paper and pressure plate measurements and (c) comparisons between different pressure plate type equipment. The latter comparisons also discuss repeatability of measurements; the discussion is then extended to filter paper measurements; as these rely on manual procedures, they were found to produce a large scatter of the data with conflicting reports on the accuracy of the technique. For instance as reported in Ridley [1] the BRE mentioned a value of $+/-25 \%$ of the mean, whereas Ridley [1] found an accuracy of $+/-10 \%$. This paper investigates this aspect further.

\section{Materials and experimental methods}

\subsection{London Clay}

The London Clay Formation is a well-developed marine geological formation found in the London Basin and

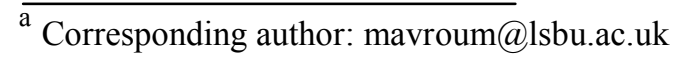

Hampshire Basin, UK reaching an average thickness of $130 \mathrm{~m}$. Up to five sedimentary cycles were identified within the London Clay (Divisions A -from the bottomto $\mathrm{E}$-to the top-), each linked to an initial marine transgression followed by a gradual shallowing of the sea. In its natural state, London Clay is a stiff overconsolidated clay, as in most parts of the London Basin, substantial erosion has taken place in the late Tertiary and Pleistocene times, removing the upper parts of the London Clay, and any other overlying Tertiary. London Clay is a material extensively encountered in construction in the London area and the South Eastern England (a very densely populated area with intensive industrial activity) including pavement construction, airports (e.g. Heathrow Terminal 5), underground railway (an example of recent engineering works being the Crossrail project), embankment and building foundation construction.

The soil used in this study was London Clay taken from an excavation at Westminster Bridge in the city of London and depths corresponding to B2 stratigraphic unit. Although at varying percentages according to location, a typical composition of London Clay with respect to its main three constituent minerals would be illite $(70 \%)$, kaolinite $(20 \%)$ and montmorillonite $(10 \%)$ although exact composition changes according to location [2]. Due to the presence of illite and also, in particular, montmorillonite, London Clay is a shrinking clay with annual surface movements due to moisture variations typically of $50 \mathrm{~mm}$ or more [3]. To identify the mineralogy of the particular London Clay used in this study XRD analysis was performed. The results are shown in Figures 1 and 2; the first figure discusses the mineral components as a whole, whereas the second focuses in particular on the clay composition. The summary of the XRD results are provided in Table 1.

The tests in this study were performed on the portion passing through a BS $425 \mu \mathrm{m}$ sieve of air dried material 
pulverised and ground in a soil grinder. The particle size distribution testing of the selected fraction shown in Figure 3 was performed in duplicate. The plasticity, specific gravity and standard Proctor compaction characteristics of this soil fraction as determined in this research are shown in Table 2.

Table 1. Mineralogical composition of the tested soil.

\begin{tabular}{|c|c|}
\hline Mineral & \% \\
\hline Smectite & 14.2 \\
\hline Illite & 27.3 \\
\hline Kaolinite & 8.19 \\
\hline Chlorite & 4.91 \\
\hline Quartz & 33.4 \\
\hline Feldspar & 5.3 \\
\hline Plagioclase & 4.1 \\
\hline Gypsum & 1.2 \\
\hline Hematite & 1.4 \\
\hline
\end{tabular}

Table 2. Basic properties of the London Clay soil.

\begin{tabular}{|c|c|c|c|c|c|}
\hline $\begin{array}{c}\mathbf{w} \\
(\mathbf{\%})\end{array}$ & $\begin{array}{c}\mathbf{w}_{\mathbf{L}} \\
(\mathbf{\% )}\end{array}$ & $\begin{array}{c}\mathbf{W}_{\mathbf{P}} \\
(\mathbf{\%})\end{array}$ & $\mathbf{G}_{\mathbf{s}}$ & $\begin{array}{c}\mathbf{w}_{\mathbf{o p t}} \\
\mathbf{( \% )}\end{array}$ & $\begin{array}{c}\mathbf{\rho}_{\mathbf{d m a x}} \\
\left(\mathbf{g} / \mathbf{c m}^{\mathbf{3}} \mathbf{)}\right.\end{array}$ \\
\hline $31 \%$ & 63.5 & 25.8 & 2.75 & 25.5 & 1.43 \\
\hline
\end{tabular}

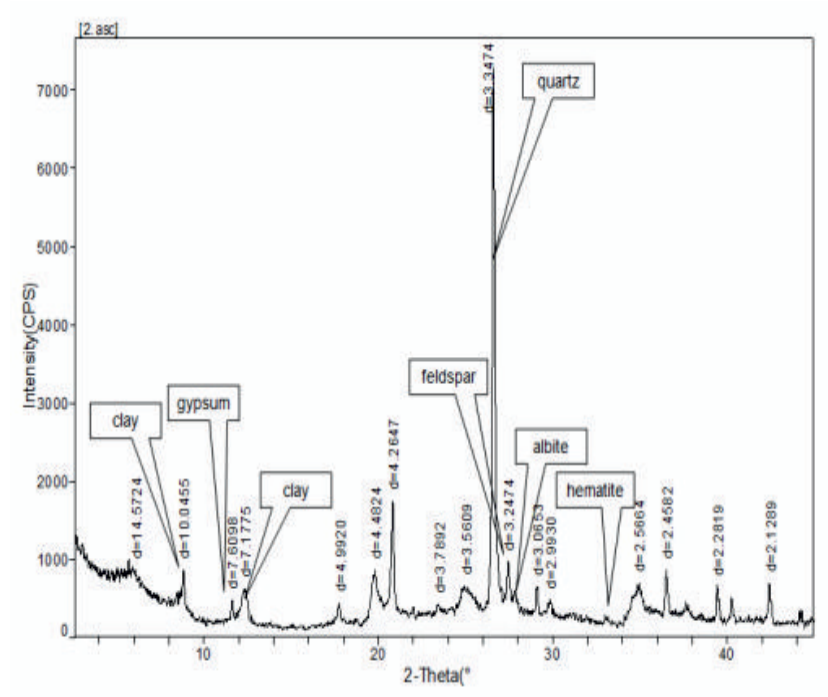

Figure 1. XRD of the whole London Clay sample.

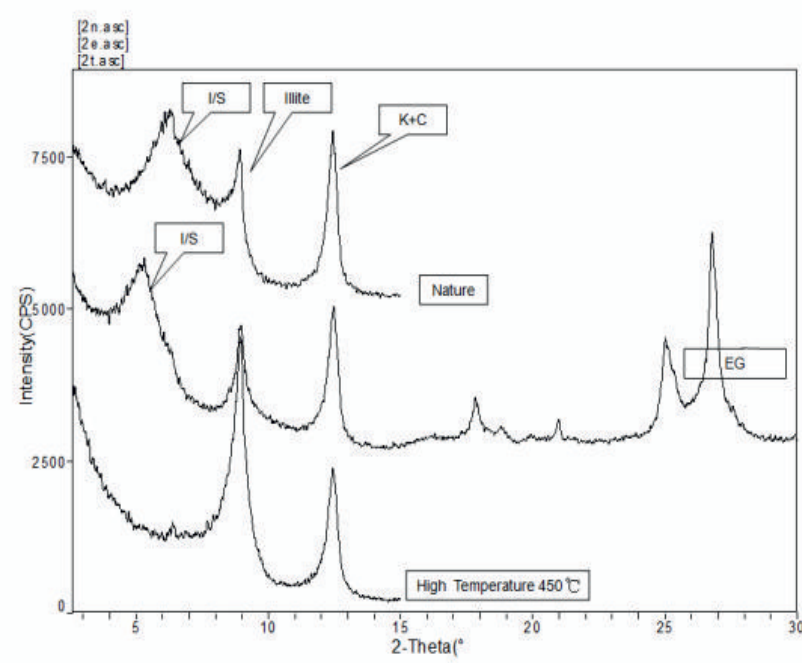

Figure 2. XRD analysis of the clay fraction.

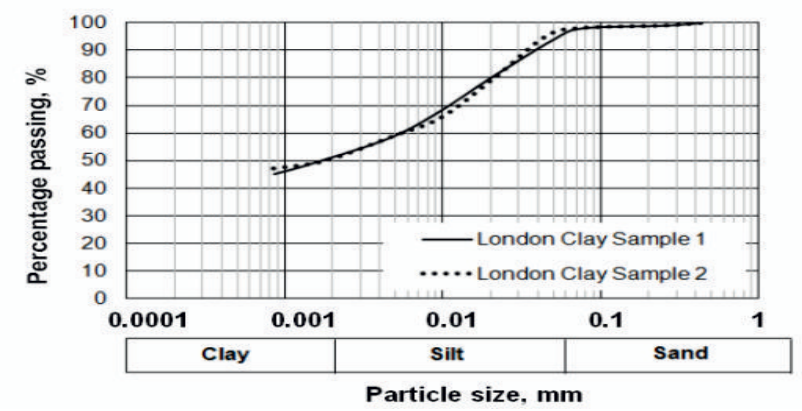

Figure 3. Particle size distribution of the tested soil.

\subsection{Specimen preparation}

The clay powder was thoroughly mixed with water at the required water content and left to hydrate in sealed bags for $72 \mathrm{~h}$. A number of statically compacted specimens were prepared in two layers at the standard Proctor maximum density of the clay. For this, a standard loading frame at a loading rate of $1 \mathrm{~mm} / \mathrm{min}$ was used. Subsequently most specimens were subject to saturation whereas a few others were tested as compacted. We used the following different saturation conditions, whose effect is assessed in this paper:

-Some specimens were left in the rings to swell freely while absorbing water through underlying porous stones standing in water.

-Some specimens were kept within standard oedometer rings $(75 \mathrm{~mm}$ diameter and $20 \mathrm{~mm}$ height approximately) and sandwiched between filter papers and porous stones in a confining frame immersed in water, especially designed to suppress any swelling during saturation, thus ensuring consistent void ratios at the beginning of each test (Fig 4). Note that it was still difficult to obtain totally identical void ratios because of some slight expansion after extruding the specimens from the cutting rings.

-To improve saturation of confined specimens some specimens (held in the confining frame) were placed in a sealed bigger cell and connected to a suction pump that vacuumed the sample for $15 \mathrm{~min}$ and water was filled slowly from the bottom of the cell. This saturation process lasted for 7 days and enabled degrees of 
saturation of as high as $95-99 \%$ to be reached.

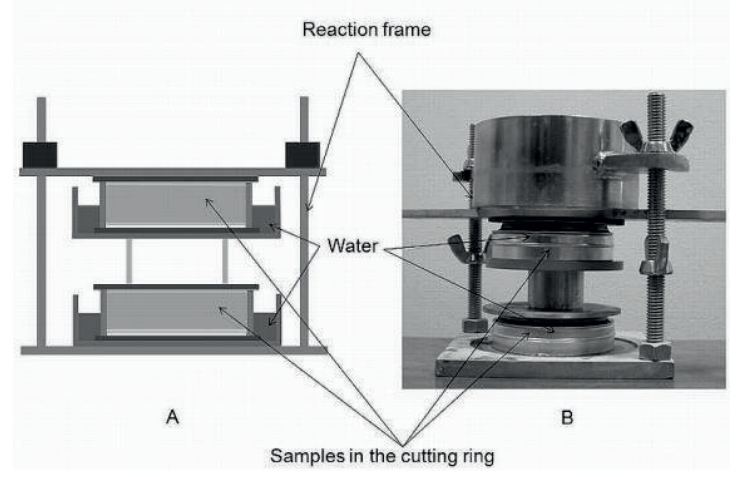

Figure 4. Saturation frame.

\subsection{Testing techniques}

The filter paper procedure used in the present research was based on ASTM D-5298 [4] with the following two main differences based on procedures developed at Imperial College, London, and presented in a number of doctoral theses (e.g. [5,6]): (i) one single soil specimen of oedometer size was used, sandwiched between two Perspex disks; three filter papers were used on each side of the specimen between the soil and the Perspex disks (ASTM D-5298 uses two equal pieces soil between which three filter papers are sandwiched); (ii) the calibration formulae according to Chandler and Gutierrez [7] and Dineen [4] were used for initially dry and wet filter paper respectively, as shown in Table 3. To obtain the drying curves the soil specimen was left to air-dry slowly to the desired water content for each measurement point, until its residual water content was reached. One single soil specimen (and not multiple 'identical' specimens at different initial water contents) was used to determine each SWRC. For the wetting curves, three wet filter papers held by tweezers were placed on either side of the specimen. The papers were soaked in distilled water until a mass of $2 \mathrm{~g}$ of water in total was absorbed by the papers. This amount of water on each side of the specimen was found to be appropriate to alleviate measurement errors due to evaporation or excessively small changes in suction.

Table 3. Calibration relationships for the filter paper.

\begin{tabular}{|c|c|c|}
\hline \multirow{2}{*}{$\begin{array}{c}\text { Initially dry } \\
\text { paper }\end{array}$} & $\begin{array}{c}\text { Filter paper } \\
\text { water } \\
\text { content, } \\
\boldsymbol{w}_{f}, \boldsymbol{\%}\end{array}$ & Matric suction, $\boldsymbol{s}, \mathbf{k P a}$ \\
\cline { 2 - 3 } & $w_{f} \leq 47$ & $s=10^{\left(4.842-0.0622 w_{f}\right)}$ \\
\hline \multirow{4}{*}{$\begin{array}{c}\text { Initially wet } \\
\text { paper }\end{array}$} & $\begin{array}{c}w_{f}>47 \\
w_{f} \leq 15.47\end{array}$ & $s=10^{\left(6.05-2.48 \log _{10} w_{f}\right)}$ \\
\cline { 2 - 3 } & $\leq 57.2$ & $S=10^{\left(4.842-0.0622 w_{f}\right)}$ \\
\cline { 2 - 3 } & $w_{f}>57.2$ & $s=10^{\left(4.573-0.0449 w_{f}\right)}$ \\
\hline
\end{tabular}

The pressure plate apparatus system designed at London South Bank University (LSBU) for this study, consisted of a rigid wall permeameter cell with a modified pedestal, incorporating a High Air Entry Value (HAEV) disk for the application of axis translation suction control technique. To prevent air leakage the HAEV disk was integrated into the base pedestal plate of the apparatus. The system was completed with a burette and a flushing device (Fig. 5).

The ceramic disc was saturated before testing. After assembling the cell the target suction was achieved by changing the air pressure accordingly using an air pressure regulator. The initial reading of the burette, was then recorded and the water outflow in the burette monitored until equilibrium was achieved (typically, 3-7 days). After suction equilibrium for each suction level the specimen was taken out of the cell for mass and volume measurements (using Vernier callipers). Following these, the specimen was placed back into the cell for the next suction level. By repeating this procedure with a stepwise increase or decrease in suction the drying or wetting branch of the SWRC were obtained accordingly.

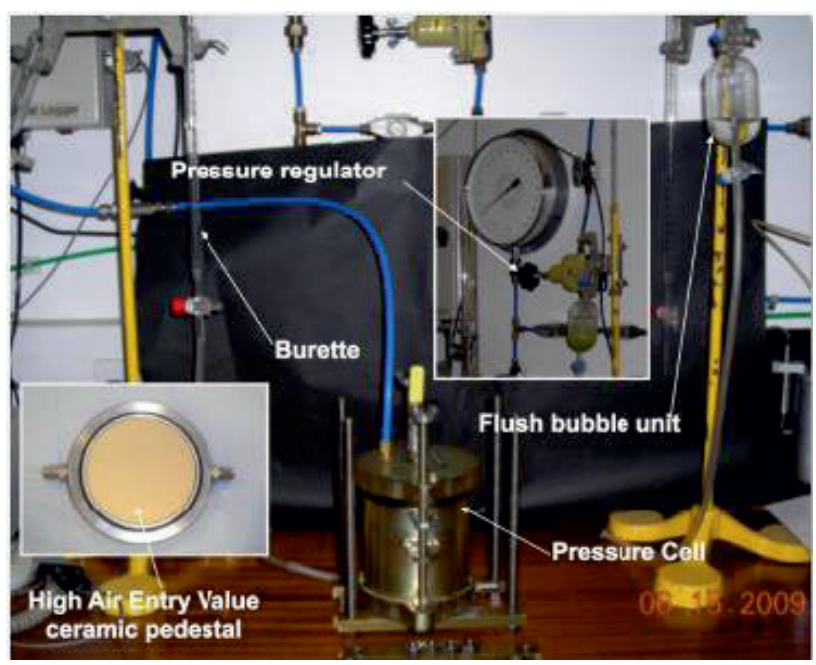

(a)

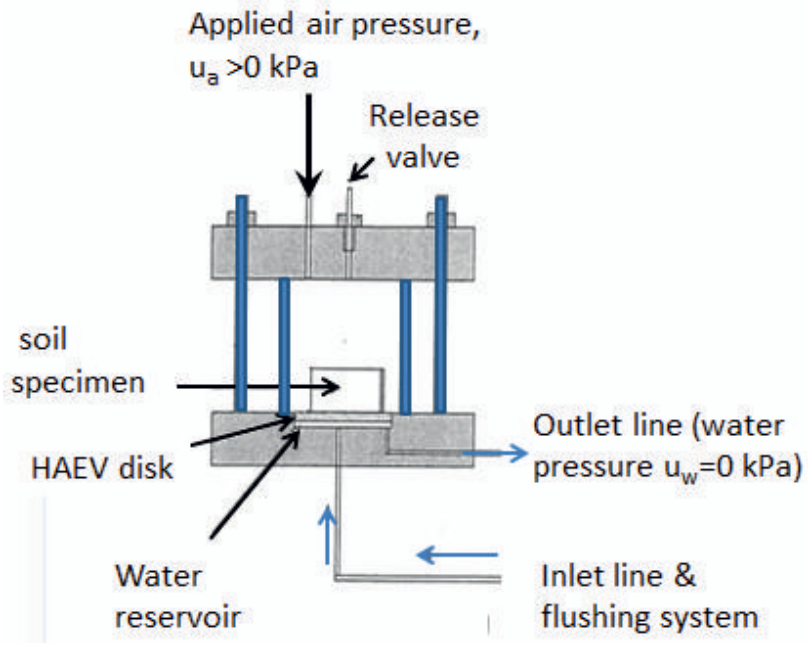

(b)

Figure 5. Pressure plate: (a) apparatus designed at LSBU; (b) schematics with applied boundary conditions. 
Two additional devices available at Beijing Jiaotong University were also used for the sake of comparisons, namely (a) a ceramic pressure membrane extractor (the most usual method of determining the SWRC in the field of soils science and hydrology); the apparatus has a membrane to the base and side of the HAEV disk, especially designed for water drainage. A wire mesh is placed between the membrane and the disk to keep an open space for water to flow. The membrane is connected to an outflow tube through a special fitting thus enabling the collected water to escape from the system (b) SWC150 Fredlund SWCC Device, a pressure plate type apparatus described in Padilla et al. [8].

\section{Experimental results}

For the sake of brevity in the following presentation of the results the notation $w-s, S_{r}-s$, and $e-s$ will refer respectively to the relationships between (a) gravimetric water content and matric suction, (b) degree of saturation and matric suction and (c) void ratio and matric suction. The first set of comparisons refers to the different saturation conditions used (Fig 6 (a)-(c)). These were confined saturation (accompanied by suction/back pressure through a GDS Instruments controller/pump) vs. unconfined saturation. For the sake of comparison results from a third specimen subjected to drying from as compacted state (i.e. without saturation) are shown. The results of the two methods of saturation are very different for all curves plotted. The $w$-s curve of the specimen saturated confined and subjected to back-pressure plots higher than that of the unconfined saturation; this is due to the fact that air was removed by vacuuming allowing better saturation of the former specimen and higher water contents (it is commonly seen that upon wetting the curves of specimens may not achieve degrees of saturation of $100 \%$ due to entrapped air; this was overcome by the application of suction). The $e-s$ curves of the confined saturation specimen plot clearly lower than those of the specimen saturated under unconfined conditions. Whereas this could have been attributed to the fact that drying of the confined specimen started at lower void ratios as no expansion was allowed during wetting, it can be observed that all void ratios of this specimen plot lower that those of the specimen subject to drying from as-compacted state, (note that the drying curve of the unconfined specimen converges with that of the ascompacted specimen). A different explanation for the lower void ratios of the confined specimen justifying the discrepancy could perhaps be the effect of vacuuming the specimen prior to applying a back-pressure which could have induced some shrinkage to the swelling-shrinking London Clay soil. As such saturation conditions are not consistent with in situ conditions and result in differences in the SWRC curves, it could be recommended that they should be avoided, even if they can lead to higher degrees of saturation.

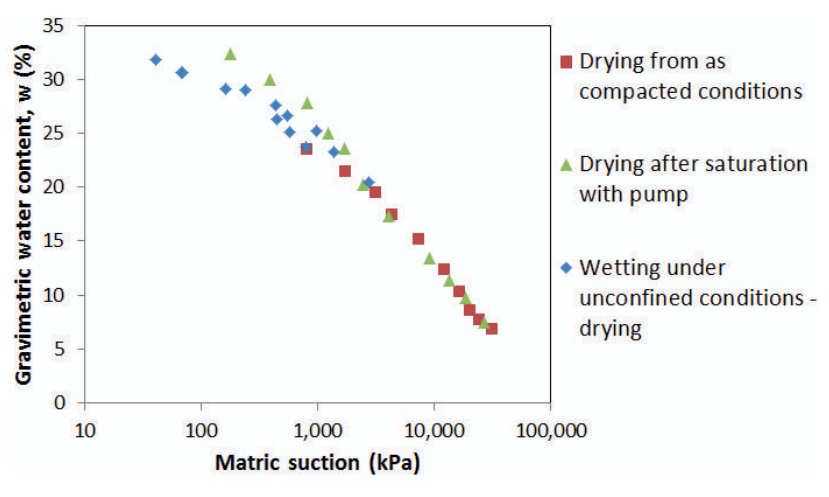

(a)

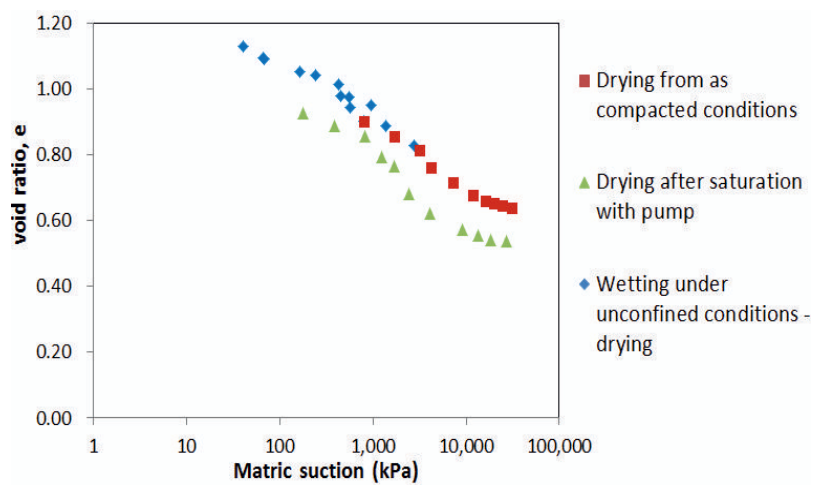

(b)

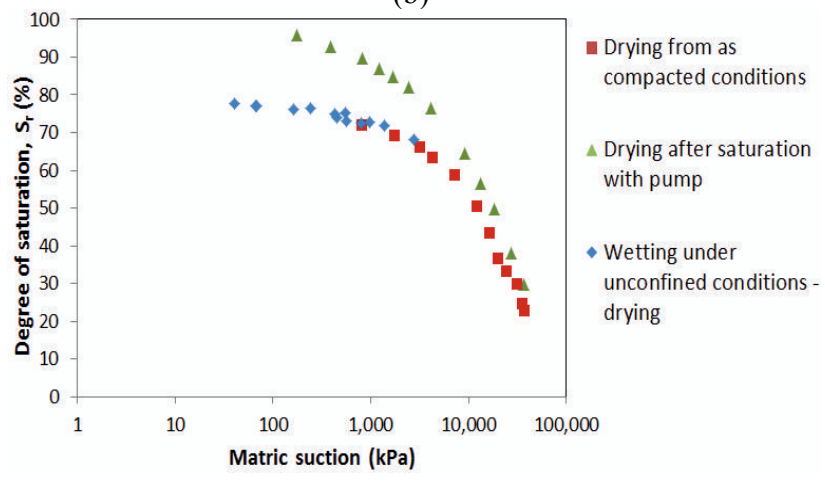

(c)

Figure 6. Comparison between different saturation conditions: (a) w-s; (b) e-s; (c) $\mathrm{S}_{\mathrm{r}}$-s.

Figure 7 shows a comparison between filter paper and pressure plate results (LSBU pressure plate apparatus). It can be seen that although the curves in general tend to converge at lower suctions, they diverge in general after air entry/maximum curvature points (see Fig 7(a) and (c)). Whereas for the $w$ - $s$ wetting curves this difference around the suction reversal could have been attributed to some scanning effect (as the path followed was a dryingwetting path) this cannot be said for the drying curves too. On the other hand it is notable that the $e-s$ drying curves coincide in the common suction region but the wetting curves do not. Namely, the void ratio changes less along the pressure plate wetting curve than is for the filter paper specimen. This trend tends to extend far beyond the reversal points. It is possible that there is some effect of the boundary conditions /air pressure on the lower void ratio change during wetting. The above 
differences are reflected in the $S_{r}-S$ curves of the two specimens (Fig 7(c)).

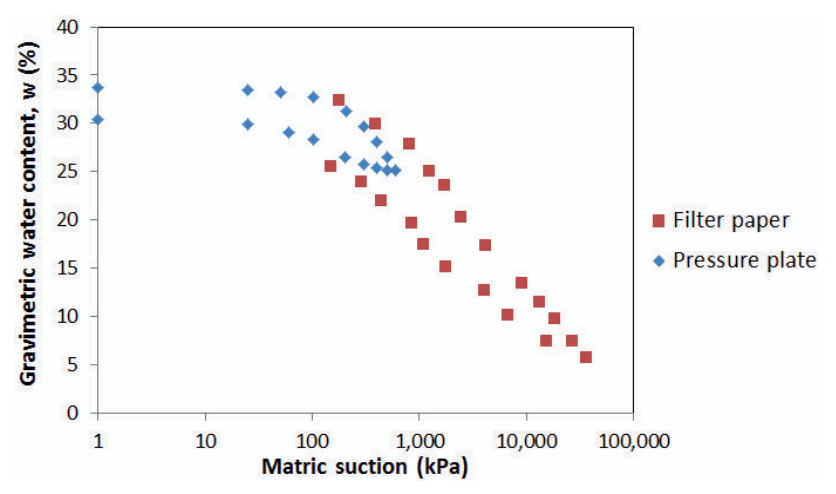

(a)

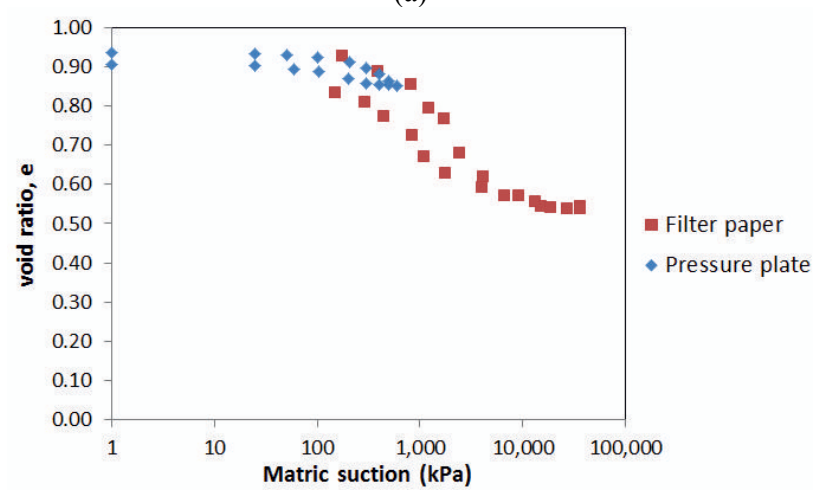

(b)

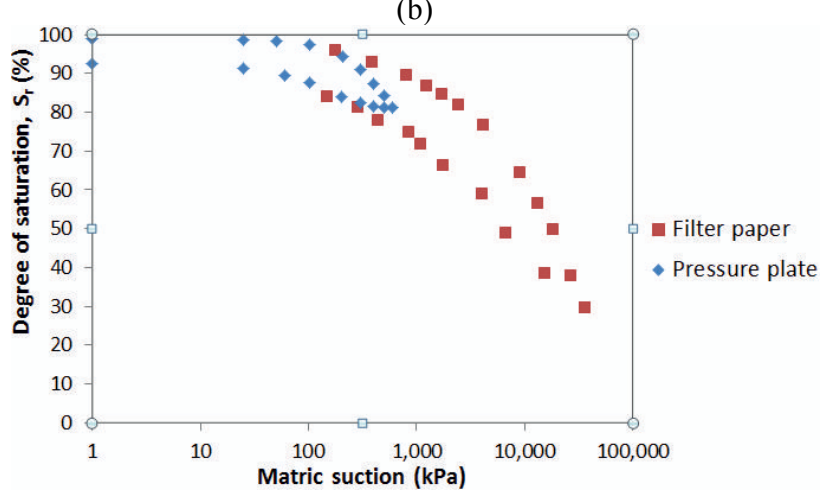

(c)

Figure 7. Comparison between pressure plate and filter paper results: (a) w-s; (b) e-s; (c) $\mathrm{S}_{\mathrm{r}}-\mathrm{s}$.

The final investigations concerned the repeatability of the measurements (Fig 8 (a)-(c) and 9(a)-(b)). First, we present results of four filter paper specimens compacted identically so that at the end of compaction they had compaction void ratios differing by a maximum of 0.008 and compaction water contents differing by a maximum of $0.4 \%$ (Fig 8(a)-(b)). The repeatability of the $w-s$ measurements is found to be excellent, with maximum differences of $+/-1.1 \%$ from the mean. On the other hand, greater differences in the $e-s$ curves can be seen, with the maximum differences from the mean being $+/-$ $4.5 \%$. In addition to human error during calliper reading this can also be due to the uncontrolled expansion of the specimens when extracted out of the rings (note that these specimens were saturated under constant volume conditions, which initially helped consistence in the void ratios across specimens). The maximum differences in the $S_{r}-S$ values are approximately $+/-2.8 \%$, which are very small compared to previously reported values.

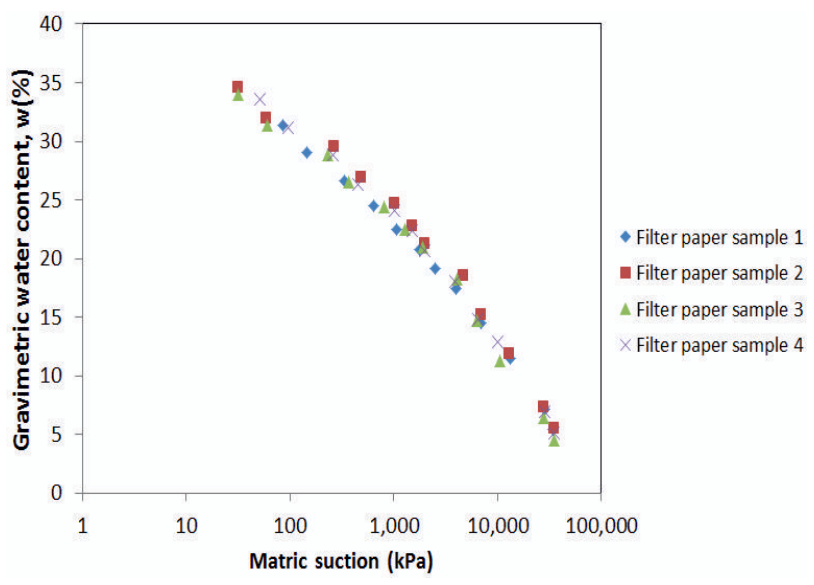

(a)

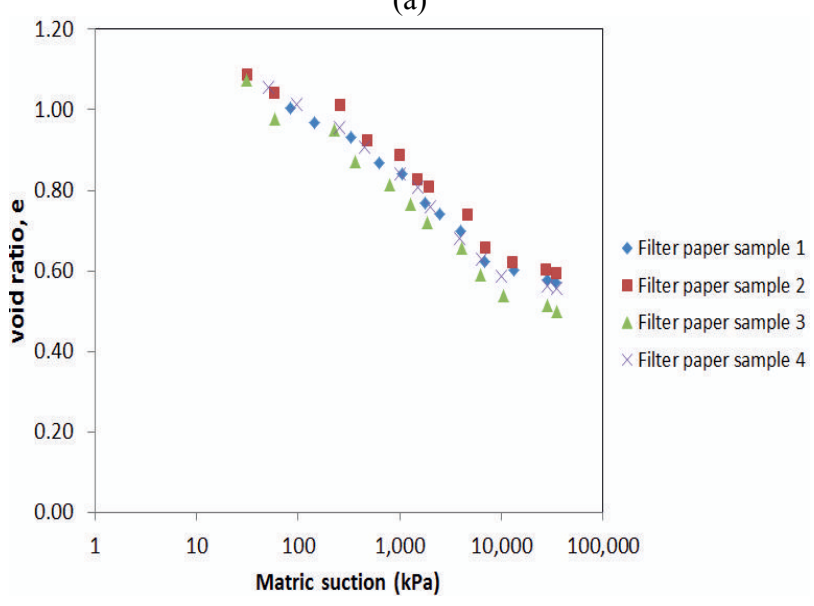

(b)

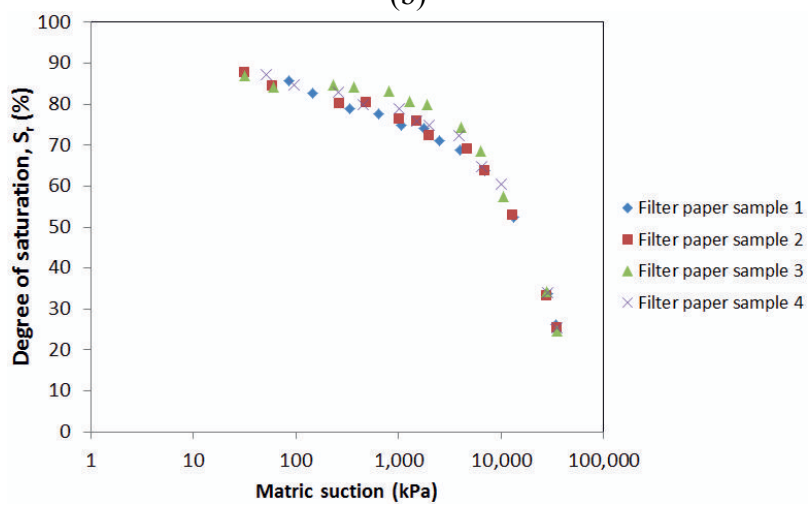

(c)

Figure 8. Repeatability of filter paper results: (a) w-s; (b) e-s; (c) $\mathrm{S}_{\mathrm{r}}-\mathrm{s}$.

Repeatability assessment was also performed using different pressure plate equipment of similar but not identical design (Fig 9(a)). Comparing LSBU pressure plate with SWC 150 Fredlund SWRC system it can be seen that the available results in terms of $w-s$ are almost identical of maximum gravimetric water content differences of approximately $0.9 \% \quad$ (Fig 9(a)); interestingly, the results of a pressure membrane extractor and pressure plate shown in Figure 9(b) are also very 
similar with maximum differences in the values of gravimetric water content of less than $1 \%$.

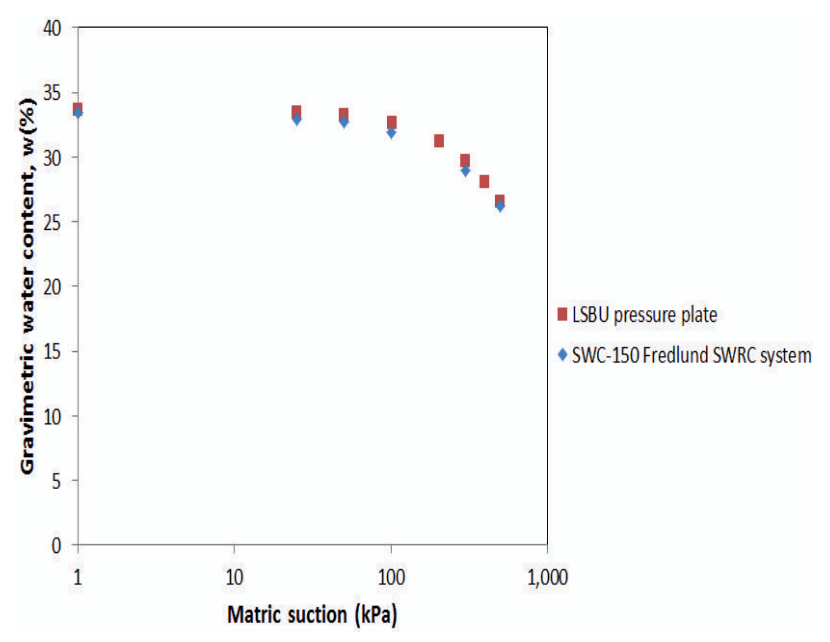

(a)

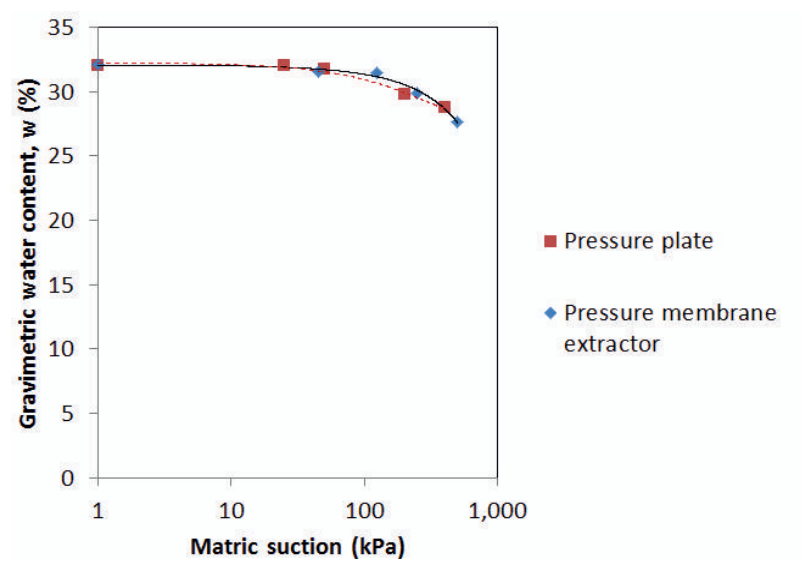

(b)

Figure 9. Repeatability of measurements using different axis translation systems: (a)LSBU pressure plate vs SWC 150 system; (b) pressure membrane extractor vs pressure plate.

\section{Further developments}

In order to directly measure suction during SWRC testing, a high suction capacity mini suction probe nominally calibrated to measure pressures of +/- 1500 $\mathrm{kPa}$ originally developed by GDS Instruments is currently being tested at London South Bank University. The probe has an overall diameter of $6.4 \mathrm{~mm}$, an inner pressure chamber of $10 \mathrm{~mm}^{3}$, a maximum nominal voltage of $125 \mathrm{mV}$ and an accuracy of $0.5 \%$ in terms of Full Scale Output (FSO). Current testing is proving the probe during London Clay and silt testing in axis translation controlled systems.

\section{Conclusions}

The paper studied the laboratory measurement of the Soil Water Retention Curve (SWRC) of statically compacted London Clay focusing on the effects of different specimen preparation methods and testing techniques to acquire a better understanding of how measurements can be affected by these factors. It was found that the repeatability of the measurements performed by the same experienced operator and following rigorous and consistent procedures was excellent. This was also the case when similar but not identical devices were used. On the other hand different saturation methods and filter paper testing versus pressure plate type measurements resulted in differences further demonstrating the need to adopt procedures close to in situ conditions, consistent with discussions in the unsaturated soil literature. To this effect, the use of a novel high capacity tensiometer is currently being tested as an alternative suction measurement technique for future tests.

\section{Acknowledgements}

This study constituted part of a larger research programme, funded by the UK Engineering and Physical Sciences Research Council (EPSRC) through grant EP/E037305/1. All tests described in this study were conducted by the first author during his doctoral studies at London South Bank University under the supervision of the co-authors. Two sets of results were conducted at Beijing University of Technology. The authors would like to thank Prof. Liu Jiankun, Beijing Jiaotong University and Prof. Yao Aijun, for their permission to conduct the latter tests in their laboratory and for their advice and support during the related experimental work.

\section{References}

1. A. M. Ridley, The measurement of soil moisture suction. $\mathrm{PhD}$ thesis (Imperial College, University of London, 1993).

2. P.G.H. Boswell, The Contribution of Clay Mineralogy to the Study of the Diagenesis of Sediments. Clay Minerals 1 (8): 246-251 (1951)

3. R. Whitlow, Basic Soil Mechanics, $4^{\text {th }}$ Ed. (Prentice, Harlow, 2001)

4. American Society for Testing and Materials (ASTM), Standard Test Method for Measurement of Soil Potential (Suction) Using Filter Paper, ASTM D 5298: 1994 (ASTM, West Conshohocken, PA 19428, 1994)

5. K. Dineen, The influence of soil suction on compressibility and swelling. $\mathrm{PhD}$ Thesis (Imperial College, University of London, 1997)

6. M. Melgarejo-Corredor, Laboratory and numerical investigations of soil retention curves. $\mathrm{PhD}$ thesis (Imperial College, University of London, 2004)

7. R. J. Chandler, C. L. Gutierrez, The filter paper method of suction measurement, Géotechnique, 36(2): 265-268 (1986)

8. J.M. Padilla, Y.Y. Perera, W.N. Houston, D.G. Fredlund, A new soil-water characteristic curve device In A. Tarantino, E. Romero \& Y.J. Cui (eds), Advanced Experimental Unsaturated Soil Mechanics - Proceedings of an International Symposium, Trento, Italy, 27-29 June 2005:15-22. (Taylor \& Francis Group, London, 2005). 